\title{
Multidisciplinary Management of Tethered Spinal Cord Syndrome in Children: Operationalizing an Outpatient Patient-Centered Workflow
}

This article was published in the following Dove Press journal: Journal of Multidisciplinary Healthcare

\author{
Mandana Behbahani ${ }^{1,2}$ \\ Nathan Shlobin ${ }^{1,2}$ \\ Colleen Rosen' \\ Elizabeth Yerkes ${ }^{3,4}$ \\ Vineeta Swaroop (D) $^{5,6}$ \\ Sandi Lam (iD) ${ }^{1,2}$ \\ Robin Bowman ${ }^{1,2}$ \\ 'Division of Pediatric Neurosurgery, Ann \\ and Robert $\mathrm{H}$ Lurie Children's Hospital \\ of Chicago, Chicago, IL, USA; \\ ${ }^{2}$ Department of Neurosurgery, \\ Northwestern University Feinberg \\ School of Medicine, Chicago, IL, USA; \\ ${ }^{3}$ Division of Pediatric Urology, Ann and \\ Robert H Lurie Children's Hospital of \\ Chicago, Chicago, IL, USA; ${ }^{4}$ Department \\ of Urology, Northwestern University \\ Feinberg School of Medicine, Chicago, IL, \\ USA; ${ }^{5}$ Division of Pediatric Orthopedic \\ Surgery, Ann and Robert $\mathrm{H}$ Lurie \\ Children's Hospital of Chicago, Chicago, \\ IL, USA; ${ }^{6}$ Department of Orthopedic \\ Surgery, Northwestern University \\ Feinberg School of Medicine, Chicago, \\ IL, USA
}

Introduction: Multidisciplinary care for patients with tethered spinal cord syndrome (TCS) is valuable in ensuring comprehensive evaluation, timely follow-up, optimal functional outcome, and patient-centered care. The family-centered focus aims to minimize patient and parental burdens associated with care coordination. We present our first-year institutional experience in operationalizing a multidisciplinary, patient-centered, pediatric tethered cord clinic (TCC) to manage routine, long-term surgical follow-up for children with nonmyelomeningocele-related tethered spinal cords.

Methods: TCC is composed of three surgical services: orthopedic surgery, neurosurgery, urology. A retrospective chart review of patients seen in the TCC from January 2019 to January 2020 was conducted. Patients enrolled in the clinic were intended for long-term follow-up. Demographic and outcome variables were collected.

Results: Fifty-nine patients were seen in TCC. Types of tethered spinal cords amongst these patients were the following: fatty filum $(62.7 \%)$, dermal sinus tract $(15.2 \%)$, meningocele manqué $(8.4 \%)$, lipomyelomeningocele $(6.7 \%)$, low lying conus medullaris $(5.1 \%)$, and sacral arachnoid cyst (1.7\%). Age at diagnosis was $1.31 \pm 2.21$ (median: 0.25 years) and at follow-up was $9.0 \pm 5.18$ years (median: 8 years). A total of $50.9 \%$ of patients were female, and $93.2 \%$ had a prior untethering procedure. Of all patients, $6.8 \%$ have no surgical intervention and continue to be monitored conservatively for evidence of decline. All three services evaluated $84.8 \%$ of patients during the same clinic session, while $15.3 \%$ of patients were seen by two of the services, and $20.3 \%$ of patients were able to schedule related imaging or diagnostic testing during the same visit.

Conclusion: We describe successful implementation of a multidisciplinary pediatric TCC and document the first year of experience. The TCC streamlines care, decreases burden on families, and reduces those lost to follow-up. Complex disease pathologies, even when clinically stable, require long-term follow-up with multiple subspecialties and benefit from multidisciplinary clinics.

Keywords: neural tube defect, tethered cord, pediatric spine, neurogenic bladder, multidisciplinary care, ambulatory efficiency

\section{Introduction}

Multidisciplinary spina bifida clinics have been described and successfully implemented in practice over many years for children with open spina bifida. ${ }^{1-6}$ These clinics allow for coordination of care and complex decision making amongst providers caring for patients with open spina bifida. High-quality integration of care between involved services such as neurosurgery, orthopedic surgery, urology,
Division of Pediatric Neurosurgery,

Director of Spina Bifida Program, Lurie

Children's Hospital, 225 E. Chicago Ave.

Chicago, IL 606 II, USA

Tel + I 3I2 2274220

Fax + I 3122279679

Email rbowman@luriechildrens.org 
rehabilitation medicine, pediatrics, psychology, physical therapy, nursing, and social work eases management and communication between a myriad of providers, maximizes the functional capacity of patients, decreases the number of work/school days lost, and reduces the attrition of patient followups. ${ }^{1,7-9}$

Tethered cord syndrome (TCS) results from various pathologies that place the spinal cord under tension. ${ }^{11}$ A majority of tethering lesions occur at the distal aspect of the spinal cord and place tension on the conus medullaris, which innervates the lower extremities, bowel, and bladder. Such pathologies are often diagnosed as part of imaging workup related to lumbosacral skin stigmata, progressive orthopedic deformity, urologic dysfunction, severe constipation, pain, and/or lower extremity weakness or sensory loss. ${ }^{9,12-16}$ Common etiologies of TCS consist of occult spinal dysraphism (OSD) such as fatty filum, dermal sinus tract, meningocele manqué, lipomyelomeningocele, myelocystocele, or split cord malformations. Less common pathologies include infectious, neoplastic, or traumatic origin. ${ }^{9,12-15}$ Although a tethered spinal cord is diagnosed by either a spinal ultrasound or MRI, only onefifth of patients with tethered cord lesions will be symptomatic at presentation. ${ }^{17}$ In order to determine the child's bowel/bladder and lower extremity functional status, an evaluation by neurosurgery, orthopedics, and urology is imperative. Formulation of an appropriate treatment plan - either surgical untethering or conservative management with long term follow-up - requires timely communication of all involved services. Timely, coordinated, and comprehensive evaluations with subsequent formulation of an appropriate treatment plan remain a major obstacle to care. ${ }^{14,18}$ Despite the advantages of a multidisciplinary clinic approach to children with spina bifida occulta/tethered spinal cords, their implementation and accessibility across medical centers are limited. ${ }^{10}$

The patient population with occult spinal dysraphism (OSD) forms of tethered cord lesions, who are managed in our Center's multi-disciplinary spina bifida clinic, can be divided based on their management approach and the point in time that they are being assessed in their disease course. Patients evaluated with OSD tethering lesions can be viewed as three groups: (i) initial assessment, documentation of baseline lower extremity and bladder/bowel function, and management recommendation, (ii) postsurgical intervention, who require long-term monitoring for possible retethering symptoms, and (iii) asymptomatic patients with radiographic evidence of a tethered cord without prior surgical intervention, who require long-term monitoring for evidence of clinical decline. In operationalizing a comprehensive tethered cord clinic (TCC), our team targeted enrolling neurologically intact patients in the last two aforementioned groups. We reason that this population is at risk to be lost to regular follow-up, given the lack of active symptoms and time pressures faced by parents/caregivers in coordinating multiple outpatient visits. Given the value of multidisciplinary care in patients with open spina bifida, ${ }^{19,20}$ we developed a pediatric tethered cord clinic at our tertiary pediatric medical center to ensure patient-centered, coordinated, comprehensive care for those patients with OSD tethered spinal cords. Here we present the rationale, steps to implementation, and our experience in operationalizing this patient-centered clinic in its first year since inception.

\section{Methods}

A retrospective chart review of patients seen in our multidisciplinary spina bifida clinic was conducted. The initial goal was to provide a forum for follow-up for the patients with a history of occult spinal dysraphism or other non-myelomeningocele tethering lesion who were neurologically intact, functionally stable, and required routine follow-up for detection of retethering or decline. The decision tree for scheduling into this clinic is shown in Figure 1. This cohort was scheduled into the TCC at our institution from January 2019 to January 2020. Demographic information such as age, sex, and race were collected. Pertinent medical information relating to symptoms at presentation, etiology of tethering, cutaneous manifestation, symptoms at presentation, referral patterns, age of surgical intervention, need for subsequent untethering procedure (before and after joining the TCC), all types of surgical intervention (neurosurgical, urologic, orthopedic), and outcome variables were collected. This study received approval by the Institutional Review Board of Ann and Robert H. Lurie Children's Hospital of Chicago. The requirement for informed consent was specifically waived by the Institutional Review Board because only deidentified data were collected. Patient data was stored securely, and confidentiality was maintained. This study was in compliance with the guidelines detailed by the Declaration of Helsinki. 


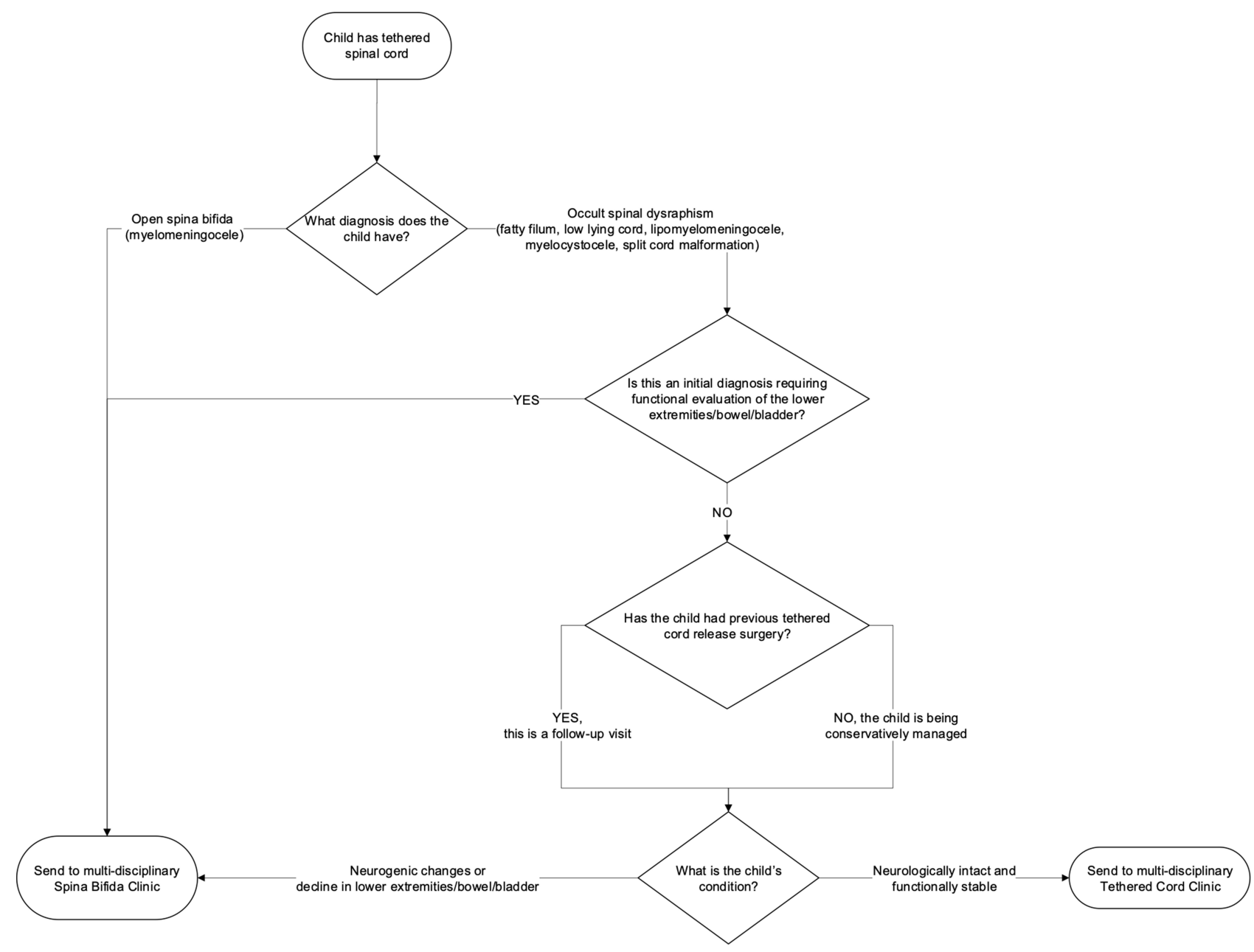

Figure I Decision tree for scheduling into the tethered cord clinic.

\section{Results}

Fifty-nine patients were seen in the TCC over the span of one year. The distribution of race consisted of $33(55.9 \%)$ white, 18 (30.5\%) Hispanic, 4 (6.8\%) Asian, 1 (1.7\%) Black, and $3(5.1 \%)$ others. Male and female distribution consisted of $29(49.15 \%)$ and $30(50.85 \%)$, respectively. Age at the time of tethered cord diagnosis had mean and median values of $1.3(\mathrm{SD}=2.2)$ and 0.3 years, respectively. Age at the time of untethering procedure had mean and median values of $2.3(\mathrm{SD}=3.3)$ and 0.8 years, respectively. These results are listed in Table 1. Ages at the time of follow-up in TCC had a mean and median of $9(\mathrm{SD}=5.2)$ and 8 years, respectively. The types of tethered cord lesions were $37(62.7 \%)$ with fatty filum, 9 (15.2\%) dermal sinus tract, $5(8.5 \%)$ meningocele manqué, $4(6.8 \%)$ lipomyelomeningocele, 3 (5.1\%) low lying conus medullaris, and $1(1.7 \%)$ sacral arachnoid cyst. Lumbo-sacral skin stigmata consisted of 27 (45.7\%) with sacral dimple,
7 (11.9\%) flammeus nevus, 3 (5.1\%) abnormal hirsutism, $2(3.4 \%)$ asymmetrical gluteal cleft, $2(3.4 \%)$ soft tissue lipoma, and 18 (30.5\%) unknown/unreported. These results are listed in Table 2. Tethered cord as part of a syndromic presentation was seen in $5(8.5 \%)$ patients. Imperforate anus was reported in $3(5.1 \%)$ patients.

All patients selected to be followed in the TCC were functionally stable and participating in long-term monitoring. Within this subgroup, a majority of patients $(55,93.2 \%)$ had previously undergone at least one prior untethering procedure, and 4 (6.8\%) were being monitored conservatively. Of those who had undergone an initial untethering, 2 patients (3.4\%) required a subsequent tethered cord release prior to joining the TCC. During this year of follow-up in the TCC, one patient, who previously had undergone an untethering, demonstrated a decline in their urodynamic studies, for which a subsequent surgical untethering was performed. While attending the TCC, one patient, previously managed 
Table I Demographics

\begin{tabular}{|c|c|c|}
\hline Age & $\begin{array}{l}\text { Age at study time } \\
\text { Age at diagnosis } \\
\text { Age at surgery }\end{array}$ & $\begin{array}{l}9.0 \text { years }(\mathrm{SD}=5.2) \\
\text { Mean } 1.3 \text { years }(\mathrm{SD}=2.2) \\
\text { Median } 0.3 \text { years } \\
\text { Mean } 2.3 \text { years }(\mathrm{SD}=3.3) \\
\text { Median } 0.8 \text { years }\end{array}$ \\
\hline Gender & $\begin{array}{l}\text { Male } \\
\text { Female }\end{array}$ & $\begin{array}{l}29(49.15 \%) \\
30(50.85 \%)\end{array}$ \\
\hline Race & $\begin{array}{l}\text { White } \\
\text { Hispanic } \\
\text { Asian } \\
\text { Black } \\
\text { Other }\end{array}$ & $\begin{array}{l}33(55.9 \%) \\
18(30.5 \%) \\
4(6.8 \%) \\
\text { I (I.7\%) } \\
3(5.1 \%)\end{array}$ \\
\hline Referral Pattern & $\begin{array}{l}\text { Pediatrician } \\
\text { Urologist } \\
\text { Dermatologist } \\
\text { Orthopedic Surgeon } \\
\text { Neurosurgeon } \\
\text { Pediatric surgeon } \\
\text { Gastroenterologist } \\
\text { Cardiologist } \\
\text { Genetics }\end{array}$ & $\begin{array}{l}39(66.1 \%) \\
5(8.5 \%) \\
3(5.1 \%) \\
2(3.4 \%) \\
2(3.4 \%) \\
2(3.4 \%) \\
2(3.4 \%) \\
2(3.4 \%) \\
1(1.7 \%)\end{array}$ \\
\hline Insurance status & $\begin{array}{l}\text { Private Insurance } \\
\text { Public Insurance }\end{array}$ & $\begin{array}{l}47(79.7 \%) \\
12(20.3 \%)\end{array}$ \\
\hline
\end{tabular}

conservatively for their tethered cord, demonstrated a new foot deformity and subsequently underwent a surgical untethering. Prior to enrollment in the TCC, 4 (6.8\%) patients required urologic procedures (excluding routine circumcision) and $1(1.7 \%)$ underwent orthopedic surgery for a lower extremity deformity. Presenting symptoms in those who underwent prior untetherings included: abnormal/worsening bladder function on urodynamic testing, back and/or lower extremity pain, recurrent urinary tract infections, infected dermal sinus tract, and meningitis. All patients in this study were independently ambulatory: 5 (8.5\%) requiring custom fitted shoe insoles and $3(5.1 \%)$ requiring other forms of orthotics at the time of their last visit.

All three respective services of orthopedic surgery, neurological surgery, and urology were able to see 50 $(84.8 \%)$ patients in the same clinic session. The remaining $9(15.2 \%)$ of patients were seen by two of the services on the same day, with the third service deemed not necessary at that visit. Additionally, $12(20.3 \%)$ patients were able to complete related imaging or diagnostic workup in the same-day visit. After their initial visit in the TCC, 59 $(100 \%)$ of patients/parents arranged subsequent follow-up
Table 2 Patient Characteristics and Clinical History

\begin{tabular}{|c|c|c|}
\hline $\begin{array}{l}\text { Tethered cord } \\
\text { etiology }\end{array}$ & $\begin{array}{l}\text { Fatty Filum } \\
\text { Dermal Sinus Tract } \\
\text { Meningocele Manqué } \\
\text { Lipomyelomeningocele } \\
\text { Low Lying Conus Medullaris } \\
\text { Sacral Arachnoid Cyst }\end{array}$ & $\begin{array}{l}37(62.7 \%) \\
9(15.2 \%) \\
5(8.5 \%) \\
4(6.8 \%) \\
3(5.1 \%) \\
1(1.7 \%)\end{array}$ \\
\hline Skin Stigmata & $\begin{array}{l}\text { Sacral dimple } \\
\text { Flammeus Nevus } \\
\text { Abnormal hairy patch } \\
\text { Gluteal cleft asymmetry } \\
\text { Swelling of lumbosacral } \\
\text { region } \\
\text { No stigmata } \\
\text { Unknown }\end{array}$ & $\begin{array}{l}27(45.7 \%) \\
7(11.9 \%) \\
3(5.1 \%) \\
2(3.4 \%) \\
2(3.4 \%) \\
14(23.7 \%) \\
4(6.8 \%)\end{array}$ \\
\hline Surgical management & $\begin{array}{l}\text { Neurosurgical procedure } \\
\text { Urologic procedure } \\
\text { Orthopedic Procedure }\end{array}$ & $\begin{array}{l}54(91.5 \%) \\
4(6.8 \%) \\
1(1.7 \%)\end{array}$ \\
\hline Outcome & $\begin{array}{l}\text { Independently Ambulatory } \\
\text { Orthotic: Shoe insoles } \\
\text { Orthotic: Other }\end{array}$ & $\begin{array}{l}59(100 \%) \\
5(8.5 \%) \\
3(5.1 \%)\end{array}$ \\
\hline Syndromic association & $\begin{array}{l}\text { Yes } \\
\text { No }\end{array}$ & $\begin{array}{l}5(8.5 \%) \\
54(91.5 \%)\end{array}$ \\
\hline Redo Surgery & $\begin{array}{l}\text { Yes } \\
\text { No }\end{array}$ & $\begin{array}{l}2(3.4 \%) \\
57(96.6 \%)\end{array}$ \\
\hline
\end{tabular}

Table 3 Multidisciplinary Care Patterns

\begin{tabular}{|l|l|}
\hline Evaluated by all 3 subspecialties & $50(84.8 \%)$ \\
Evaluated by all 2 subspecialties & $9(15.2 \%)$ \\
$\begin{array}{l}\text { Ancillary testing (Imaging, urologic testing) or Physical } \\
\text { therapy on the day of appointment }\end{array}$ & $12(20.3 \%)$ \\
Comprehensive Follow-up & $59(100 \%)$ \\
\hline
\end{tabular}

through this multidisciplinary clinic. These results are listed in Table 3.

The initial referral pattern in this population included a majority from pediatricians $(39,66.1 \%)$, followed by urology $(5,8.5 \%)$, dermatology $(3,5.1 \%)$, and orthopedics, pediatric surgery, neurosurgery, gastroenterology, and cardiology contributing 2 (3.4\%) each, 1 (1.7\%) referred from genetics, and $1(1.7 \%)$ unknown. The referral pattern based upon region (as delineated by zip code for the patient's residence) revealed a catchment area from all over the state of Illinois and neighboring states (Figure 2). The payer status for patients included $47(79.7 \%)$ private insurance and 12 (20.3\%) public insurance. 


\section{Discussion}

We captured a subgroup of patients with various etiologies of spina bifida occulta associated with tethered spinal cords, many of whom had previously undergone a spinal cord untethering procedure. This group of patients were enrolled in a multidisciplinary TCC allowing coordinated comprehensive follow-up in a timely manner. Here we describe the development and implementation of our multidisciplinary pediatric TCC and document the first years' experience. To the best of our knowledge, this is the first such clinical report outlining the utility, demographics, and outcomes of a multidisciplinary clinic for patients with a tethered cord not associated with open spina bifida. Our goal is to expand this clinic into a comprehensive referral center for the initial diagnosis, evaluation, and long-term follow-up of children with spina bifida occulta forms of tethered spinal cords.
The TCC was helpful in enhancing communication, coordinating comprehensive care, providing timely management decision, as well as easing the burden of followups on the patients and their families. Rate of compliance for patient evaluation by all three surgical subspecialties was satisfactory. Such compliance is consistent with previous studies noting coordination of care among providers in dedicated multidisciplinary spina bifida clinics. ${ }^{1-6}$ Given the multitude of etiologies and presenting symptoms, ${ }^{9,12-16}$ it is essential that all surgical subspecialties are present in one clinic to coordinate management of patients with TCS. Coordination of care allowed for clear patient-centered communication to improve health literacy $^{8,11}$ and streamline clinical visits, for both patients and providers. TCC was held at family-friendly hours in the late afternoon up to $7 \mathrm{pm}$, aimed at minimizing days lost from work or school. ${ }^{21}$ These factors decreased the

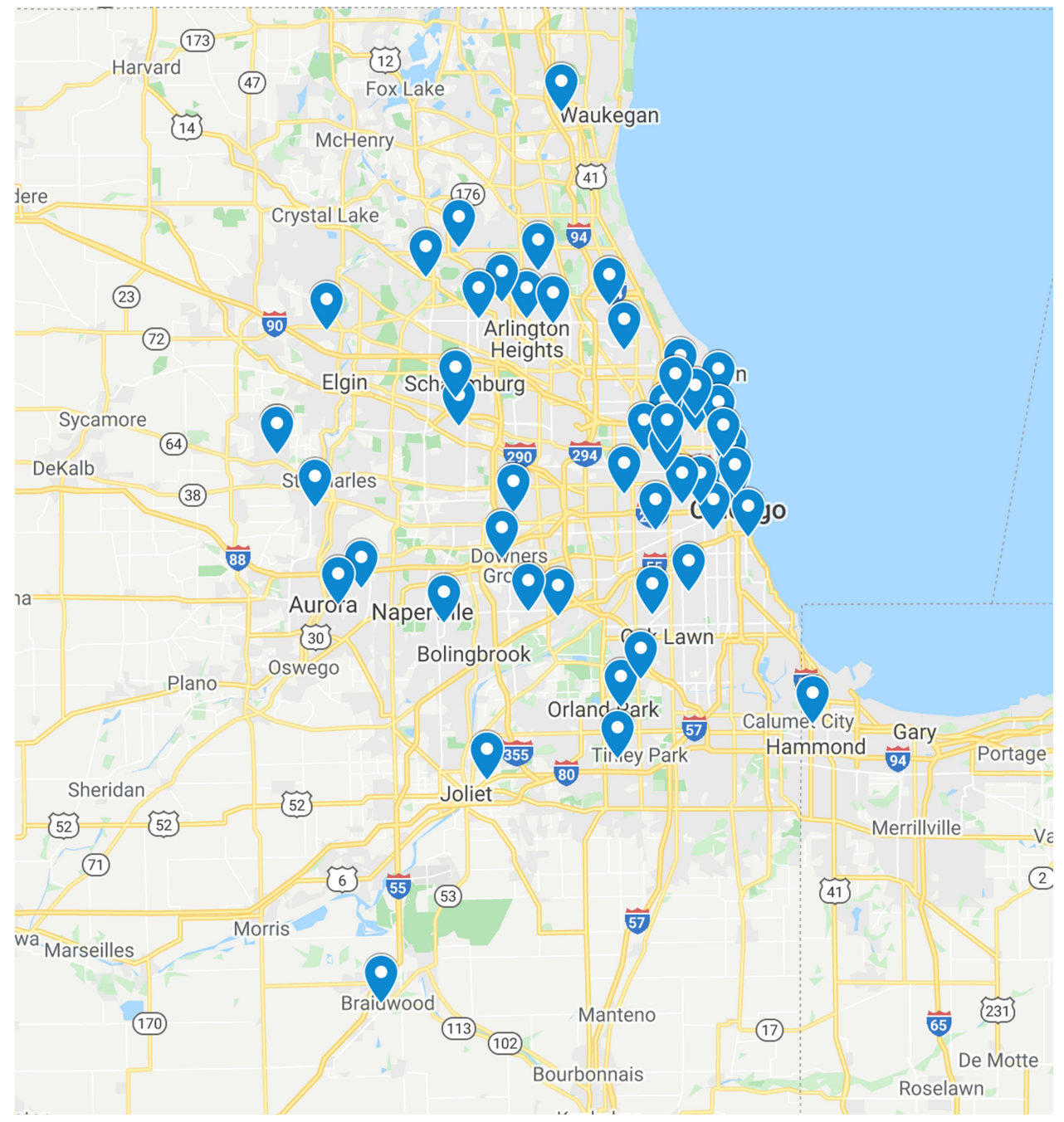

Figure 2 Map showing geographical origin of patients for tethered cord clinic. 
burden of care for families ${ }^{1}$ by providing them with a more manageable schedule of appointments for their children. Testing to be completed prior to TCC provider assessment, including a manual muscle test (MMT), renal bladder ultrasound (RBUS) and/or urodynamic studies, was to be completed within sixty days of provider followup in the TCC. Completion of TCC testing within sixty days of the individual's TCC provider assessments was chosen specifically to allow for families to schedule this follow-up at a time best suitable for them. Additionally, we chose a less medically demanding subgroup of patients, who were otherwise medically stable, completed their acute surgical follow-up, and required annual monitoring for symptoms of retethering or decline. All patients enrolled in this clinic were previously being evaluated by each corresponding service and approved as suitable for the TCC. Collectively, information regarding treatment approaches consisting of monitoring for pain and mobility, strength assessment, urological evaluation, and evaluation for spinal or lower extremity deformity was gathered.

Multidisciplinary spina bifida clinics are common, with 104 clinics in the United States alone. ${ }^{22}$ Most clinics include a urologist, social worker, nurse practitioner or nurse coordinator, and physical therapist, while others may have a neurosurgeon, orthopedist, pediatrician, orthotist, nutritionist, and physiatrist specific to the clinic. ${ }^{22}$ At our institution, our multidisciplinary TCC incorporates providers from neurosurgery, orthopedic surgery, and urology, while orthotists and therapists are auxiliary, allowing comprehensive care for patients with TCS. While loss to follow-up occurs in patients with spina bifida, ${ }^{16}$ TCC promotes retention of patients by providing a comprehensive and satisfactory experience for patients and families in a timely manner. While the TCC is aimed at a select group of stable patients, our goal is to expand our comprehensive clinic to include all OSD/tethered cord patients, most notably those at the time of diagnosis and initial work up. Multidisciplinary spina bifida clinic has been a standard of care at our hospital since $1975,{ }^{16}$ while the TCC is not yet standardized for all patients with TCS managed at our institution.

As the TCC expands, there are numerous areas for improvement that have come to light. First, a truly comprehensive clinic not only allows patients to be seen by surgical subspecialties, but also allows for coordination of the necessary testing as part of the comprehensive evaluation. Although the number of patients evaluated by all three subspecialties attest to the success of this comprehensive clinic, a smaller percentage of patients had their diagnostic testing on the same day. Integrating testing into patient visits will further reduce the burden on families. ${ }^{1}$ Second, using the electronic medical record to generate a single comprehensive note template with all pertinent common data elements and after visit summary would allow all subspecialties to document their recommendations and streamline the feedback to patients and families, as well as the primary care physician. We are refining one unified letter and summary with all subspecialty service feedback combined to make the feedback and plans from the multidisciplinary clinic timely, understandable, and salient to patients and primary care providers. Use of comprehensive note templates and use of common data elements are important for clinical care, communication with other healthcare providers, and data collection for research. In the future, we plan to incorporate more standardization of note templates into our clinic model, using the International Classification of Functioning, Disability, and Health developed with the World Health Organization (WHO) (https://apps.who.int/iris/handle/ 10665/43737). Third, the TCC initially only included patients in long term follow-up. Expanding the TCC to include all initial patient evaluations will enhance timely management decision making, improve parental understanding of pathology, and allow for expansion of a dedicated tertiary referral center with a robust catchment area. Lastly, once a patient's baseline function is established, some select subsequent visits may be able to be transitioned to a telemedicine video evaluation. Many families travel long distances for treatment at our Center. The next step in improvement would be better utilization of telemedicine to minimize travel time and expense for families when medically appropriate. ${ }^{24}$ Telemedicine would allow the TCC to expand its catchment referral patterns to incorporate patients from greater distances. Currently, the radius of patients enrolled in this clinic is captured in Figure 1, which highlights the need for accommodating travel time to ensure thorough follow-ups. For future program development, additional planning for transition of care into adulthood will be an important component with lifelong surveillance in an integrated adult healthcare system.

The experience in coordinating care in the TCC was not without difficulties. In multidisciplinary spina bifida clinics, challenges to care include strong presence of all three surgical subspecialties in one institution, cohesive working relationship between providers, staffing, 
clinic day logistics, community resources, and familyrelated concerns. ${ }^{1,20}$ However, the benefits to care coordination outweigh these challenges ${ }^{1}$ and process-based changes in the operations of the TCC can be made to address these challenges.

\section{Limitations}

Limitations of this study are in part due to the small number of TCS patients who are currently enrolled in TCC. Moreover, the retrospective study design has inherent limitations. Quality and process improvement starts on a local scale: the details of the implementation of this clinic may not be entirely generalizable, but the goals of a multidisciplinary care model apply to many pediatric conditions. Regional practice variation may also limit generalizability. Consideration of local patient populations and practice settings are necessary to apply the TCC model to different children's hospitals and healthcare settings. The sociodemographic representation of this clinic may not reflect the pediatric patient population in our urban practice: this finding spurs ongoing re-evaluation of our tethered cord population to gauge possible disparities in detection, referral, treatment, and follow-up. This study is the first to present a specialized multidisciplinary tethered cord clinic, making it difficult to compare our approach and outcomes to other studies; however, it is important to share knowledge about the challenges experienced and lessons learned about multidisciplinary patient-centered, coordinated care in the service of optimizing delivery of care for pediatric patients with TCS.

Further study is warranted from patient, family, provider, community, and healthcare perspectives. This initial descriptive study documents our pilot in implementation of a tethered cord clinic. As clinical volumes grow, we anticipate there will be lessons in the scalability of this coordinated, multidisciplinary, family-centered care. With a larger sample size and ongoing evaluation, it will be feasible to the measure quality of care and impact of this clinic on the three surgical services' ambulatory enterprise as well as the direct and indirect costs to the family and the institution.

\section{Conclusion}

We describe the development and implementation of a multidisciplinary pediatric tethered cord clinic and document the experience from the first 12 months. We highlight the successes and challenges of this clinic, as well as improvements to further reduce the burden of care on patients and families. Further study is warranted from patient, family, provider, community, and healthcare perspectives.

\section{Acknowledgments}

This manuscript was supported by a generous grant from the Kiwanis Neuroscience Research Foundation. The authors thank the research coordinator team Klaudia Dziugan and Marcellus Johnson for support services.

\section{Disclosure}

Elizabeth Yerkes reports grants from Kiwanis, during the conduct of the study. The authors report no other potential conflicts of interest in this work.

\section{References}

1. Brustrom J, Thibadeau J, John L, et al. Care coordination in the spina bifida clinic setting: current practice and future directions. J Pediatr Health Car. 2012;26(1):16-26. doi:10.1016/j.pedhc.2010.06.003

2. Sawin KJ, Liu T, Ward E, et al. The national spina bifida patient registry: profile of a large cohort of participants from the first 10 clinics. J Pediatr. 2015;166(2):444-450. e441. doi:10.1016/j. jpeds.2014.09.039

3. Rocque BG, Ralee'Bishop E, Scogin MA, et al. Assessing health-related quality of life in children with spina bifida. J Neurosurg Pediatr. 2015;15(2):144-149.

4. Campbell JB, Moore KN, Voaklander DC, et al. Complications associated with clean intermittent catheterization in children with spina bifida. J Urol. 2004;171(6 Part 1):2420-2422. doi:10.1097/01. ju.0000125200.13430.8a

5. Szymanski KM, Cain MP, Hardacker TJ, et al. How successful is the transition to adult urology care in spina bifida? A single center 7-year experience. J Pediatr Urol. 2017;13(1):40. e41-40. e46. doi:10.1016/ j.jpurol.2016.09.020

6. Ramachandra P, Palazzi KL, Skalsky AJ, et al. Shunted hydrocephalus has a significant impact on quality of life in children with spina bifida. $P M \& R$. 2013;5(10):825-831. doi:10.1016/j.pmrj.2013.05.011

7. Chehroudi C, MacNeily A. Further thoughts on transition of care for spina bifida patients: experiences in BC. Can Urol Assoc J. 2016;10 (11-12):377. doi:10.5489/cuaj.4249

8. Lightfoot MA, Cheng JW, Hu X, et al. Assessment of health literacy in adolescents with spina bifida and their caregivers: a multi-institutional study. J Pediatr Urol. 2020;16(2):167-e1.

9. Rekate HL. The pediatric neurosurgical patient: the challenge of growing up. Paper presented at: Seminars in pediatric neurology; 2009.

10. Kinsman S, Levey E, Ruffing V, et al. Beyond multidisciplinary care: a new conceptual model for spina bifida services. European J Pediatr Surg Rep. 2000;10(S 1):35-38. doi:10.1055/s-2008-1072413

11. Yamada S, Won DJ, Pezeshkpour G, et al. Pathophysiology of tethered cord syndrome and similar complex disorders. Neurosurg Focus. 2007;23(2):1-10. doi:10.3171/FOC-07/08/E6

12. Lew SM, Kothbauer KF. Tethered cord syndrome: an updated review. Pediatr Neurosurg. 2007;43(3):236-248. doi:10.1159/000098836

13. Bui CJ, Tubbs RS, Oakes WJ. Tethered cord syndrome in children: a review. Neurosurg Focus. 2007;23(2):1-9. doi:10.3171/FOC-07/ 08/E2

14. Sanchez T, John RM. Early identification of tethered cord syndrome: a clinical challenge. J Pediatr Health Car. 2014;28(3):e23-e33. doi:10.1016/j.pedhc.2013.06.007 
15. Lad SP, Patil CG, Ho C, et al. Tethered cord syndrome: nationwide inpatient complications and outcomes. Neurosurg Focus. 2007;23 (2):1-5. doi:10.3171/FOC-07/08/E3

16. Bowman RM, McLone DG, Grant JA, et al. Spina bifida outcome: a 25-year prospective. Pediatr Neurosurg. 2001;34(3):114-120. doi: $10.1159 / 000056005$

17. Tuuha SE, Aziz D, Drake J, et al. Is surgery necessary for asymptomatic tethered cord in anorectal malformation patients? J Pediatr Surg. 2004;39(5):773-777.

18. Bradko V, Castillo H, Janardhan S, et al. Towards guideline-based management of tethered cord syndrome in spina bifida: a global health paradigm shift in the era of prenatal surgery. Neurospine. 2019;16(4):715. doi:10.14245/ns.1836342.171

19. Calado E, Loff C. The failures of spina bifida transdisciplinary care. Eur J Pediatr Surg. 2002;S51-S52.
20. Brei TJ. The future of the multidisciplinary clinic. Sci World J. 2007; 7:1752-1756.

21. Palfrey JS, Sofis LA, Davidson EJ, et al. The pediatric alliance for coordinated care: evaluation of a medical home model. Pediatrics. 2004;113(Supplement 4):1507-1516.

22. Thibadeau J, Walker WO Jr, Castillo J, et al. Philosophy of care delivery for spina bifida. Disabil Health J. 2020;13(2):100883.

23. Gibbons C, Coyle D, White C, et al. Assessment of neurogenic bowel symptoms with the bowel dysfunction score in children with spina bifida: a prospective case-control study. Pediatr Surg Int. 2020;1-5.

24. Liptak GS, El Samra A. Optimizing health care for children with spina bifida. Dev Disabil Res Rev. 2010;16(1):66-75. doi:10.1002/ ddrr.91

\section{Publish your work in this journal}

The Journal of Multidisciplinary Healthcare is an international, peerreviewed open-access journal that aims to represent and publish research in healthcare areas delivered by practitioners of different disciplines. This includes studies and reviews conducted by multidisciplinary teams as well as research which evaluates the results or conduct of such teams or healthcare processes in general. The journal covers a very wide range of areas and welcomes submissions from practitioners at all levels, from all over the world. The manuscript management system is completely online and includes a very quick and fair peer-review system. Visit http://www.dovepress.com/testimonials. php to read real quotes from published authors. 